\title{
PENGARUH PENEMPATAN KARYAWAN TERHADAP KINERJA KARYAWAN PADA PABRIK KELAPA SAWIT 1 BUKIT PAYUNG KABUPATEN KUNTAN SINGINGI
}

\section{Effect of Employee Placement on the Performance of Emplyees in Factory Payung Palm Hills District I Kuantan Singingi}

\author{
Fahrial ${ }^{1}$ ), Andri Romanto ${ }^{2}$ ) \\ ${ }^{1)}$ Dosen Program Studi Agribisnis Fakultas Pertanian Universitas Islam Riau \\ ${ }^{2)}$ Alumni Mahasiswa Prodi Manajemen Sekolah Tinggi Ilmu Ekonomi Riau \\ Email :fahrial2018@ agr.uir.ac.id \\ [Diterima: Januari 2017; Disetujui: April 2018)
}

\begin{abstract}
This study aimed to determine the effect of staffing on the performance of employees at mills I Bukit Kuantan District Singingi Umbrella all employees mills I Mount Umbrella, sampling technique using simple random sampling as many as 57 people. In analyzing the data of this study data analysis using descriptive and quantitative methods, namely by processing the data obtained from the company, then analyzed using the theoretical basis as a means to solve problems, and then make a conclusion. The research result is seen from the results of the $t$-test where the value $t$ count $>t$ table $(32,639>2,004)$ there is a significant positive influence between the placement of employees on employee performance. Judging from the coefficient of determination R Square of 0,951. This shows that the percentage contribution of staffing influence on employee performance is at $95 \%$. While the remaining $5 \%$ is influenced by other variables not included in the study.
\end{abstract}

Keywords: Employee Placement and Performance

\begin{abstract}
Penelitian ini bertujuan untuk mengetahui pengaruh penempatan karyawan terhadap kinerja karyawan pada Pabrik Kelapa Sawit 1 Bukit Payung Kabupaten Kuantan Singingi seluruh karyawan pabrik Kelapa Sawit 1 Bukit Payung.Teknik pengambilan sampel menggunakan Simple Random Sampling sebanyak 57 orang. Dalam menganalisis data penelitian ini analisis data menggunakan metode diskriptif kuantitatif yaitu dengan mengolah data yang diperoleh dari perusahaan tersebut, kemudian dianalisis dengan menggunakan landasan teori sebagai alat untuk memecah masalah yang dihadapi, dan kemudian mengambil suatu kesimpulan.Hasil penelitian dari hasil uji t dimana nilai $\mathrm{t}$ hitung $>t$ table $(32,639>2,004)$ terdapat pengaruh secara positif yang signifikan antara penempatan karyawan terhadap kinerja karyawan. Dilihat dari koefisien diterminasi R Squer sebesar 0,951 ini menunjukkan bahwa persentase sumbangan pengaruh penempatan karyawan terhadap kinerja karyawan adalah sebesar 95\%.Sedangkan sisanya sebesar 5\% dipengaruhi oleh variable lain yang tidak dimasukkan dalam penelitian ini.
\end{abstract}

Kata kunci: Penempatan Karyawan dan Kinerja

\section{PENDAHULUAN}

Dalam setiap kemajuan Perusahaan diperlukan karyawan yang tangguh dan ulet guna memenangkan persaingan kerja yang dinamis. Untuk itu karyawan tersebut harus bias meningkatkan kualitas dan kuantitas kerja serta sikap jujur, memiliki loyalitas yang tinggi. Agar terbentuknya karyawan yang professional dan berdedikkasdi tinggi.Oleh sebab itu sumber daya manusia memegang andil besar dalam keberhasilan dan kemajuan perusahaan.

Pemberian pekerjaan atau alokasi sumber daya manusia kepada tenaga kerja baik yang 
baru direkrut maupun pekerja yang sudah lama bekerja. Penempatan tenaga kerja merupakan factor penting dalam mempekerjakan karyawan yang sesuai dengan keterampilan atau pengetahuannya di jabatan atau kedudukan tertentu dalam organisasi.

Permasalah penempatan karyawan berdampak kepada tidak tercapainya target produksi perusahaan, artinya tidak maksimalnya kinerja dari karyawan, faktor penyebabnya adalah proses penempatan karyawan namun penempatan yang tepat tidak cukup untuk menunjang kinerja karyawan, melainkan membutuhkan pengalaman untuk menunjang pekerjaan tersebut. Karyawan dengan pengalaman kerja akan lebih mudah melaksanakan pekerjaan, dibandingkan dengan karyawan lama dan baru tidak bias disamakan.

Dari data diketahui bahwa selama lima tahun terakhir target dan realisasi produksi pabrik kelapa sawit 1 Bukit Payung tidak pernah mencapai target yang telah ditentukan, pada tahun 2009 target produksinya adalah 40.540 ton dan terealisasi 39.700 ton atau sebesar $97,92 \%$ pada tahun 2010 target produksinya adalah 41.350 ton dan terealisasi 37.800 ton atau sebesar $91,41 \%$, pada tahun 2011 target produksinya adalah 43.600 ton dan terealisasi 40.900 ton atau sebesar $93,80 \%$, pada tahun 2012 target produksinya adalah 45.900 ton dan terealisasi 42,350 ton atau sebesar $92,26 \%$, pada tahun 2013 target produksinya adalah 44.700 ton dan terealisasi 43.100 ton atau sebesar $92,26 \%$.

Berdasarkan permasalahan yang ditemukan di lapangan bahwa dalam penempatan karyawan belum menggunakan pendristribusian karyawan dengan tepat yang sesuai dengan kebutuhan suatu bagian.Sehingga berpengaruh terhadap kinerja.

\section{METODOLOGI PENELITIAN}

Penelitian ini mengambil lokasi di Pabrik Kelapa Sawit 1 Bukit Payung Kabupaten Kuantan Singingi. Dalam penelitian ini menggunakan dua data yaitu 1.Data primer yang diperoleh melalui pengumpulan data langsung dari sampel yang diolah sesuai dengan kebutuhan penelitian yaitu tanggapan dan pendapat responden mengenai penempatan karyawan terhadap pelakasanaan tugas pada pabrik Kelapa Sawit 1 Bukit Payung
Kabupaten Kuantan Singingi. 2. Data sekunder yaitu data yang diperolah langsung dari Pabrik Kelapa Sawit 1 Bukit Payung Kabupaten Kuantan Singingi, meliputi jumlah karyawan Perusahaan Kelapa sawit 1 dan struktur organisasi perusahaan kelapa sawit 1 .

Dalam penelitian ini populasi adalah seluruh karyawan Pabrik Kelapa Sawit I Bukit Payung yang berjumlah 135 orang.Teknik pengambilan sampel menggunakan Simple Random Sampling yaitu pengambilan sampel anggota populasi dilakukan secara acak tanpa memperhatikan strata yang ada dalam populasi itu. Dengan demikian setiap unit sampling sebagai unsur populasi yang terpencil memperoleh peluang yang sama untuk menjadi sampel atau untuk mewakili populasi karena anggota populasi dianggap homogeny (Sekaran, 2006). Besarnya ukuran sampel dalam penelitian ini ditentukan dengan menggunakan rumus slovin (dalam Riduwan, 2005) yaitu $\mathrm{n}=\mathrm{N} /\left(1+\mathrm{N}(\mathrm{e})^{2 .}\right.$ Diketahui jumlah populasi 135 dan batas ketelitian 0,01 maka jumlah sampel $(n)=135 /\left(1+135(0,01)^{2}\right.$ adalah $135 /(1+1,35)=57$ orang.

Dalam usaha mengumpulkan data dan informasi yang diperlukan oleh penulis untuk penulisan penelitian ini, penulis menggunakan metode sebagai berikut :

1. Angket / Daftar questioner. Maka penulis menggunakan skala likers yaitu masingmasing jawaban responden diberi skor 1 5 yaitu (Sugiyono, 2008) dimana sangat setuju (SS), setuju (S), cukup setuju (CS), tidak setuju (TS) dan sangat tidak setuju (STS). Kemudian untuk mengetahui ratarata jawaban responden digunakan interval kelas yang di dapat dari rumus :

Interval $=($ Niai skor tertinggi - Nilai skor terendah)/ Banyak kelas $=(5-1) / 5=0,8$

2. Interview, dengan mengadakan interview langsung dengan responden tentang penempatan karyawan.

Di dalam menganalisis data yang telah dikumpulkan, maka penulis menggunakan metode analisis deskriptif kuantitatif. Menurut Suharsimi Arikunto (2010), deskirptif adalah membandingkan antara kenyataan yang sebenarnya dengan teori-teori yang ada hubungannya dengan permasalahan guna menarik kesimpulan dan ditabulasikan dalam bentuk table-tabel distribusi frekwensi. Sedangkan metode kuantitatif menurut 
Sugiyono (2008), adalah penelitian berdasarkan pada data yang dapat dihitung untuk menghasilkan penaksiran yang kokoh. Untuk mengetahui seberapa besar pengaruh penempatan karyawan terhadap kinerja karyawan, dengan menggunakan analisis regresi sederhana dengan rumus : $\mathrm{Y}=\mathrm{a}+\mathrm{bX}$.

Dimana: $\quad \mathrm{Y}=$ Kinerja karyawan

$\mathrm{X}=$ Penempatan Karyawan

$\mathrm{a}=$ Konstanta

$\mathrm{b}=$ Koefisien regresi.

Untuk menguji hipotesis di atas dilakukan uji t. Uji t dilakukan untuk mengetahui variable yang mempengaruhi variable $\mathrm{t}$ terikat. Jika $\mathrm{p}<\alpha(0,05)$ maka Ho ditolak dan $\mathrm{H} 1$ diterima, artinya terdapat factor yang signifikan dari penempatan karyawan terhadap kinerja karyawan pada Pabrik Kelapa Sawit I Bukit Payung Kabupaten Kuantan Singingi.

\section{HASIL DAN PEMBAHASAN}

\section{Data Identitas Responden}

Berdasarkan dari kelompok umur responden rata-rata umur responden $31-45$ tahun dan berdasarkan jenis kelamin dimana sebanyak 47 orang adalah $82,46 \%$ responden laki-laki dan 10 orang responden atau $17,54 \%$ responden perempuan. Jadi rata-rata responden adalah laki-laki.Berdasarkan rata-rata pendidikan responden yang pendidikan terakhir responden adalah SMA.

\section{Data Identitas Responden}

\section{A. Penempatan Karyawan}

Jadi rata-rata responden menyatakan setuju terhadap penempatan karyawan dari kemampuan untuk jenis pekerjaan yang dibebankan sudah sesuai dengan rata-rata bobot sebesar 4,19. Jadi rata-rata responden menyatakan setuju terhadap penempatan karyawan dengan kecakapan di tingkat SD, SMP, SMA dengan rata-rata bobot 4,12. Jadi rata-rata responden menyatakan setuju terhadap penempatan karyawan dengan kecakapan di tingkat pendidikan sarjana sudah tepat dengan rata-rata bobot sebesar 4,25, artinya sangat setuju. Jadi rata-rata responden menyatakan sangat setuju terhadap penempatan karyawan menurut keahlian pada bagian labor sudah tepat, ini dapat dilihat dari rata-rata bobot sebesar 4,89, artinya sangat setuju. Jadi ratarata responden menyatakan setuju terhadap penempatan karyawan menurut keahlian pada bagian timbangan sudah tepat, ini dapat dilihat dari rata-rata bobot sebesar 4,18 , artinya setuju. Jawaban responden tentang penempatan karyawan dengan rata-rata 4,32, artinya responden menyatakan setuju terhadap penempatan karyawan pada Pabrik Kelapa Sawit I Bukit Payung Kabupaten Kuantan Singingi

\section{B. Kinerja}

Jadi rata-rata responden menyatakan setuju terhadap pelayanan yang tepat waktu dan berkualitas, ini dapat dilihat dari rata-rata bobot sebesar 3,87, artinya setuju. Jadi rata-rata responden menyatakan setuju terhadap tingkat keterampilan pendidikan yang sesuai dengan bidang kerja, ini dapat dilihat dari rata-rata bobot sebesar 3,77, artinya setuju. Jadi rata-rata responden menyatakan setuju terhadap tingkat kehadiran /keterlambatan karyawan yang selalu tepat waktu, ini dapat dilihat dari rata-rata bobot sebesar 3,98, artinya setuju. Dari uraian di atas dapat dilihat bahwa jawaban responden tentang kinerja dengan rata-rata skor sebesar 3,87 , ini termasuk kategori setuju, ini berarti bahwa responden menyatakan setuju terhadap kinerja karyawan pada pabrik Kelapa Sawit I Bukit Payung Kabupaten Kuantan Singingi. Didapat nilai rata-rata tertinggi dari tanggapan terhadap penempatan karyawan yakni item pertanyaan 5 dengan nilai rata-rata 4,89 dan nilai terendah yakni pada item pertanyaan 2 dengan nilai rata-rata 4,12 .

\section{Uji Validitas}

Validitas adalah ketepatan atau kecermatan suatu instrument dalam mengukur apa yang ingin diukur. Pengujian validitas dilakukan dengan menggunakan metode Bivarate Pearson yang selanjutnya diolah dengan menggunakan program SPSS versi 18.Didapat $r$ table sebesar 0,261.Untuk uji validitas variable penempatan karyawan dapat disimpulkan bahwa masing-masing item pertanyaan pada variable penempatan karyawan telah valid.Sedagnakan untuk uji validitas 
variable kinerja karyawan dapat disimpulkan bahwa masing-masing item pertanyaan pada variable kinerja karyawan telah valid.

\section{Uji Reliabilitas}

Uji reliabilitas digunakan untuk mengetahui konsistesi alat ukur, apakah alat pengukur yang digunakan dapat diandalkan dan tetap konsisten jika pengukuran tersebut diulang. Dalam penelitian ini metode yang dgunakan adalah metode Alpha (Cronbach's). Adapun nilai $r$ table (uji 2 sisi) pada signifikansi 0,05 dengan jumlah data $(\mathrm{n})=57$, di dapat sebesar 0,261.

\section{E. Uji Normalitas}

Uji normalitas digunakan untuk mengetahui apakah populasi data berdistribusi normal atau tidak, dengan menggunakan taraf signifikansi 0,05 . Data dinyatakan berdistribusi normal jika signifikansi lebih besar dari $0,05 \%$. Adapun nilai signifikansi variable penempatan karyawan yaitu 0,077 dan variabel kinerja 0,057 . Karena nilai signifikansi seluruh variabel lebih besar dari 0,05 dapat disimpulkan bahwa data pada setiap variabel berdistribusi normal.

\section{F. Analisis Regresi Linear Sederhana}

Analisis ini digunakan untuk mengetahui pengaruh variabel bebas insentif terhadap variabel terikat kinerja karyawan.Setelah diolah dengan menggunakan SPSS versi 18.Dari hasil pengolahan dengan SPSS versi 18 di dapat diperoleh persamaan regresi sebagai berikut adalah:

$$
\begin{aligned}
& Y=a+b X \\
& Y=-9,338+0,828 X
\end{aligned}
$$

Persamaan ini dapat diartikan sebagai berikut :

$>$ Konstanta sebesar (-9,338); artinya jika variabel bebas $\mathrm{X}$ (penempatan karyawan) nilainya adalah 0 , maka variabel terikat $\mathrm{Y}$ (kinerja karyawan) nilainya yaitu sebesar (9.338).

$>$ Koefisien regresi varabel $\mathrm{X}$ (penempatan karyawan) sebesar 0,828, artinya jika penempatan karyawan mengalami kenaikan sebesar 1 poin maka kinerja karyawan juga akan mengalami kenaikan sebesar 0,828. Koefisien bernilai positif artinya terjadi hubungan positif antara penempatan karyawan dengan kinerja karyawan. Semakin naik variabel penempatan karyawan maka kinerja karyawan juga akan semakin naik.

\section{G. Analisis Koefisien Determinasi R Square $\left(\mathbf{R}^{2}\right)$}

Dari hasil pengolahan dengan SPSS versi 18 diperolah angka $R$ Square $\left(R^{2}\right)$ sebesar 0,951 atau $95 \%$.Hal ini menunjukkan bahwa persentase sumbangan pengaruh variabel bebas (penempatan karyawan) terhadap variabel terikat (kinerja karyawan) adalah sebesar $95 \%$. Sedangkan sisanya sebesar 5\% dipengaruhi oleh variabel lain yang tidak dimasukkan dalam penelitian ini.

\section{H. Pengujian Koefisien Regresi (Uji t)}

Dari hasil analisis regresi output dapat disajikan terlihat nilai t hitung adalah 32.639. Untuk melakukan uji $\mathrm{t}$ maka dilakukan langkah-langkah sebagai berikut :

$>$ Menentukan hipotesis nihil dan hipotesis alternative.

Ho : $\beta=0$; tidak ada pengaruh secara signifikan penempatan karyawan terhadap kinerja karyawan pada Pabrik Kelapa Sawit I Bukit Payung Kabupaten Kuantan Singingi.

$\mathrm{H} 1: \beta=0$; terhadap kinerja karyawan pada Pabrik Kelapa Sawit I Bukit Payung Kabupaten Kuantan Singingi.

$>$ Menantentukan tingkat signifikansi.

Tingkat signifikansi penelitian ini adalah $\alpha$ $=5 \%$ atau 0,05

$>$ Menentukan t hitung. Berdasarkan table diperoleh $\mathrm{t}$ hitung sebesar 32,639

$>$ Menentukan t table.

Tabel distribusi $\mathrm{t}$ dicari pada $\alpha=5 \%$ dengan rumus sebagai berikut :

$\mathrm{t}(\underline{\pi}, \mathrm{n}-\mathrm{k})=\mathrm{t}(0,025,55)=2,004$

$>$ Kriteria pengujian.

Ho diterima jika $-\mathrm{t}$ table $<\mathrm{t}$ hitung $<\mathrm{t}$ table.

Ho ditolak jika t hitung $>1$

Table atau $-\mathrm{t}$ hitung $<-\mathrm{t}$ table. 
Membandingkan $\mathrm{t}$ hitung dengan $\mathrm{t}$ table. Nilai $\mathrm{t}$ hitung > $\mathrm{t}$ table $(32,639>2,004)$ maka Ho ditolak.

$>$ Kesimpulan :

Oleh karena nilai $\mathrm{t}$ hitung $>\mathrm{t}$ table $(32,639$ > 2,004) maka Ho ditolak, artinya terdapat pengaruh yang signifikan antara penempatan karyawan terhadap kinerja.Jadi dapat disimpulkan bahwa penempatan karyawan berpengaruh positif terhadap kinerja.

\section{KESIMPULAN}

1. Untuk mengukur pengaruh penempatan karyawan terhadap kinerja karyawan pada Pabrik Kelapa Sawit I Bukit Payung Kabupaten Kuantan Singingi meliputi $X=$ variabel penempatan karyawan dan $\mathrm{Y}=$ variabel kinerja.

2. Untuk menguji keberartian koefisien regresi untuk melihat pengaruh dimensi penempatan karyawan terhadap kinerja karyawan pada pabrik kelapa sawit I Bukit Payung Kabupaten Kuantan Singingi dilakukan dengan uji t. Dari hasil penelitian diperolah nilai thitung > 1 tabel $(32,639>2,004)$, sehingga t hitung lebih besar dari t table dengan demikian terdapat pengaruh seara positif yang signifikan antara penempatan karyawan terhadap kinerja karyawan. Dilihat dari koefisien diterminansi R Square sebesar 0,951 hal ini menunjukkan bahwa persentase sumbangan karyawan terhadap kinerja karyawan adalah sebesar 95\%. Maka disimpulkan terdapat pengaruh yang signifikan antara penempatan karyawan terhadap kinerja.

\section{DAFTAR PUSTAKA}

Abdullah, Thamrin, dan Tantri 2012, Manajemen PemasaranBadan Pusat Statistik.2016. Riau Dalam Angka.Badan Pusat Statistik Provinsi Riau, Pekanbaru.

Arikunto, Suharsimi 2010, Prosedur Penelitian Suatu Pengantar Praktek. Rineka Cipta. Jakarta.

Riduwan, 2005. Belajar Mudah Penelitian Untuk Guru, Karyawan dan Peneliti Pemula, Bandung : Alfabeta.

Sekaran, Uma, 2003. Research Method for Business.John Wiley and Sons, Inc New York.

Sugiyono, 2008. Metode Penelitian Adminstrasi. Alfabeta. Bandung. 
